\title{
Differences in acute ischaemic stroke care in Poland: analysis of claims database of National Health Fund in 2017
}

\author{
Michał Maluchnik ${ }^{1}$, Danuta Ryglewicz ${ }^{2}$, Halina Sienkiewicz-Jarosz ${ }^{2}$, Adam Kobayashi ${ }^{3,4}$ \\ Maria Barcikowska-Kotowicz ${ }^{5}$, Barbara Więckowska ${ }^{6}$, Bartosz Karaszewski ${ }^{7}$, Maciej Niewada ${ }^{8}$ \\ ${ }^{1}$ Ministry of Health, Poland \\ ${ }^{2} 1$ st Department of Neurology, Institute of Psychiatry and Neurology, Warsaw, Poland \\ ${ }^{3}$ Interventional Stroke and Cerebrovascular Disease Treatment Centre, Institute of Psychiatry and Neurology, Warsaw, Poland \\ ${ }^{4}$ Kazimierz Pulaski University of Technology and Humanities, Radom, Poland \\ ${ }^{5}$ Department of Neurodegenerative Disorders, Mossakowski Medical Research Centre, Polish Academy of Sciences, Warsaw, Poland \\ ${ }^{6}$ Warsaw School of Economics, Social Insurance Department, Warsaw, Poland \\ ${ }^{7}$ Department of Adult Neurology, Medical University of Gdansk, Gdansk, Poland \\ ${ }^{8}$ Department of Experimental and Clinical Pharmacology, Medical University of Warsaw, Warsaw, Poland
}

\begin{abstract}
Selected and basic indicators of acute ischaemic stroke care in Poland are reported cross-regionally based on the analysis of claims data of the National Health Fund (NFZ) in 2017, the most reliable source of healthcare funding in the country, being a single public payer.

For research purposes, a selection algorithm based on the diagnosis coded as 163 according to the International Classification of Diseases (ICD-10) was used to identify all ischaemic stroke patients in the claims database provided by the NFZ. Stroke units and other centres providing treatment for acute ischaemic stroke patients were examined. The analysis showed marked differences between provinces in terms of stroke unit treatment availability. The crude and standardised rates of acute ischaemic stroke admissions to stroke units varied between provinces. Moreover, substantial differences were observed for the thrombolysis implementation rate, access to rehabilitation, hospital stay and early prognosis. As the leading cause of disability and the second leading cause of death in developed countries, stroke requires a well-organised, evidence-based healthcare system provided for both acute treatment and rehabilitation. Continuous monitoring of healthcare is crucial to identify weaknesses and areas for improvement.
\end{abstract}

Key words: acute ischaemic stroke, thrombolysis, rehabilitation, mortality

(Neurol Neurochir Pol 2020; 54 (5): 449-455)

\section{Background}

Being the second greatest cause of death in developed countries, and the leading cause of complex permanent disability, stroke requires well-organised and evidence-based healthcare for both acute treatment and rehabilitation [1]. A comprehensive and equally distributed system of stroke care delivery is needed to manage emergency services, acute care in stroke units, and to provide rehabilitation. Continuous monitoring of healthcare quality indicators in reference to changing epidemiological data is crucial to identify any weaknesses and areas for improvement.

Evidence-based treatment of ischaemic stroke includes, broadly, management in stroke units (defined as an organised in-hospital facility entirely devoted to caring for patients with stroke and staffed by a multidisciplinary team with specialist knowledge and experience carrying out stroke-specific and general care procedures), recanalisation and reperfusion (either thrombolysis or thrombectomy, or both), aspirin for early recurrence prevention, and decompressive craniectomy $[2,3]$. Moreover, early prevention and rehabilitation are beneficial

Address for correspondence: Michał Maluchnik, Ministry of Health, Poland, e-mail: michal.maluchnik@gmail.com 
for the treatment process, and therefore require quick and appropriate application.

The first Polish population-based study showed stroke mortality failed to decline between 1984 and 1992, with neither case fatality nor stroke incidence declining [4]. As a consequence, national programmes to improve stroke care were implemented. Both the National Programme for Stroke Prevention and Treatment and the subsequent National Programme for Prevention and Treatment of Cardiovascular Diseases (POLKARD) were mainly focused on supporting stroke units and evidence-based stroke care. Both programmes monitored selected indicators of acute stroke care, although reporting data to a stroke registry was not mandatory [5, 6]. Registry-based studies demonstrated significant differences in patient characteristics, acute hospital care, and outcomes among participating centres [7] as well as the so called 'weekend effect'. Such differences can result from not only stroke severity but also stroke care quality and organisation [8].

Improvement in stroke risk and prognosis was first reported by a study comparing data from the Warsaw Stroke Registry (1992) and the European Register of Stroke (2005). Although incidence rates did not change, early (30-day) and late (1-year) case fatality decreased significantly, from $43 \%$ to $14.9 \%$ and from $59.7 \%$ to $33.1 \%$ respectively [9].

Some projects were also implemented at a regional level, and mostly reported similar findings [10-13].

All of these initiatives had limited national representativeness until the 2008 Hospital Stroke Registry initiation brought about mandatory reporting on stroke patients admitted to hospital. Data for 2009-2013 showed a slow improvement in in-hospital survival [14]. Unfortunately, even the 2008 Hospital Stroke Registry collected only limited and basic information, that moreover was not reported systematically and remained unverified. There has been no recent robust, comprehensive and representative data on acute stroke care, nor in particular data combining the use of recanalisation/reperfusion interventions and early rehabilitation.

Diagnosis related groups were introduced in 2008 to provide principal diagnosis-orientated hospital care funding in Poland. The Maps of Healthcare Needs (MPZ) project was aimed at analysing data collected by public institutions to identify current clinical practice and healthcare service provision, and also to specify prognosis for healthcare and to implement continuous monitoring. This was the first comprehensive approach to monitoring healthcare systematically across different therapeutic areas and covering the entire system in both hospital and outpatient settings.

The objective of this paper was to illustrate acute ischaemic stroke care in various provinces of Poland based on the data reported by hospitals to the National Health Fund (NFZ), as well as information collected by the Central Statistical Office and Department of National Central Evidences run by the
Ministry of Internal Affairs and Administration in 2017 and pooled within the MPZ project.

\section{Methods}

A selection algorithm based on the diagnosis coded as I63 according to the International Classification of Diseases (ICD-10) was used to identify all ischaemic stroke patients in the database of hospital healthcare services covered by the NFZ. Additionally, early survival of patients could be tracked using their national identification number (PESEL).

Stroke patients' rates were presented as crude numbers and values standardised by age and gender for each of 16 administrative provinces. Stroke hospital admission rates were presented as numbers per 100,000 inhabitants.

Stroke units providing treatment for acute ischaemic stroke patients were explored. Stroke units were identified not only as registered in the Central Register of Healthcare Centres but additionally as centres reporting specific dedicated DRG codes (A48 - comprehensive treatment of stroke patients in stroke units lasting longer than seven days, and A51 - thrombolytic therapy of patients treated in stroke units for longer than seven days). Given that these DRG codes specific to stroke units can be reported for patients hospitalised for 7+ days only, the analysis also included other stroke-related DRG codes for all healthcare service centres.

Thrombolysis rates were calculated based on the reported number of procedures of thrombolysis (ICD-9 code: 99.102 - intravenous infusion of second-generation thrombolytic agent and related specific codes $\mathbf{9 9 . 1 0 1}, \mathbf{9 9 . 1 0 3 , 9 9 . 1 0 4 ) ~ f o r ~ a l l ~}$ admitted ischaemic stroke patients and presented separately for each province. In addition, we reported the number of stroke centres delivering thrombolysis, the number of stroke units with thrombolysis rates of over $10 \%$, and the corresponding rates of patients hospitalised in these centres across all provinces. Corresponding data was calculated for acute rehabilitation reported within 30 days of stroke onset during the initial hospital stay.

'Hospital stay' was calculated as the difference between the admission date and the discharge or in-hospital death date, and presented as a median for each province and range between in-province centres with the lowest and highest median values of length of stay.

Early mortality rate was calculated for 10 days, 30 days and 90 days starting from hospital admission, and was adjusted for age and sex.

\section{Statistical analysis}

Descriptive statistics were presented for the entire country and each province. Standardisation was made for the European population [15]. In-hospital and early mortality rates were presented as crude mean values and additionally adjusted for age and sex. 
Table 1. Ischaemic stroke patient characteristics and hospital admissions - 2017

\begin{tabular}{|c|c|c|c|c|c|c|c|c|}
\hline Province & $\begin{array}{c}\text { General } \\
\text { population }\end{array}$ & $\begin{array}{l}\text { Number of } \\
\text { ischaemic } \\
\text { stroke } \\
\text { admissions }\end{array}$ & $\begin{array}{l}\text { Mean } \\
\text { age }\end{array}$ & $\begin{array}{c}\text { Sex } \\
\text { ( } \% \text { of fe- } \\
\text { males) }\end{array}$ & $\begin{array}{c}\text { Number } \\
\text { of stroke } \\
\text { units }\end{array}$ & $\begin{array}{l}\text { Number of } \\
\text { large stroke } \\
\text { units (>200 } \\
\text { patients ho- } \\
\text { spitalised) }\end{array}$ & $\begin{array}{l}\text { Number of } \\
\text { large stroke } \\
\text { units (>300 } \\
\text { patients ho- } \\
\text { spitalised) }\end{array}$ & $\begin{array}{c}\text { Percentage } \\
\text { of patients } \\
\text { hospitalised } \\
\text { in stroke units }\end{array}$ \\
\hline Dolnośląskie & 2902,365 & 5,684 & 72.21 & 50.14 & 11 & 11 & 9 & 77.67 \\
\hline $\begin{array}{l}\text { Kujawsko- } \\
\text {-Pomorskie }\end{array}$ & 2082,935 & 4,008 & 73.26 & 51.49 & 10 & 8 & 6 & 97.38 \\
\hline Lubelskie & 2129,260 & 4,365 & 73.80 & 49.48 & 14 & 8 & 7 & 89.64 \\
\hline Lubuskie & 1016,652 & 2,555 & 72.30 & 52.67 & 5 & 4 & 3 & 88.67 \\
\hline Łódzkie & 2479,962 & 5,391 & 71.45 & 50.35 & 11 & 10 & 7 & 65.07 \\
\hline Małopolskie & 3386,162 & 6,105 & 72.03 & 51.02 & 15 & 14 & 10 & 85.96 \\
\hline Mazowieckie & 5372,579 & 9,589 & 72.50 & 50.25 & 24 & 20 & 15 & 90.87 \\
\hline Opolskie & 991,161 & 2,109 & 74.02 & 54.80 & 3 & 3 & 2 & 93.66 \\
\hline Podkarpackie & 2127,687 & 4,208 & 73.29 & 50.01 & 16 & 11 & 2 & 90.40 \\
\hline Podlaskie & 1185,174 & 2,155 & 73.89 & 49.20 & 4 & 4 & 3 & 79.77 \\
\hline Pomorskie & 2319,735 & 4,578 & 71.81 & 48.23 & 11 & 9 & 8 & 96.78 \\
\hline Śląskie & 4552,627 & 10,007 & 72.68 & 48.62 & 24 & 21 & 15 & 86.95 \\
\hline Świętokrzyskie & 1249,710 & 2,905 & 73.22 & 48.06 & 7 & 7 & 3 & 97.14 \\
\hline $\begin{array}{l}\text { Warmińsko- } \\
\text {-Mazurskie }\end{array}$ & 1434,783 & 2,849 & 72.91 & 52.00 & 7 & 6 & 4 & 75.55 \\
\hline Wielkopolskie & 3484,975 & 6,625 & 70.97 & 46.15 & 12 & 12 & 9 & 73.14 \\
\hline $\begin{array}{l}\text { Zachodniopo- } \\
\text { morskie }\end{array}$ & 1706,579 & 3,194 & 71.38 & 45.43 & 7 & 7 & 5 & 90.75 \\
\hline Poland & 38422,346 & 76,327 & 72.29 & 49.42 & 181 & 155 & 108 & 85.66 \\
\hline
\end{tabular}

\section{Results}

The total number of ischaemic stroke hospital admissions in 2017 amounted to 76,327 and was reported for a total of 72,983 patients with a mean age of 72.29 years (the age of $34.8 \%$ of patients was 80 or older). The great majority of patients were managed in stroke units $(85.66 \%)$, while the remaining patients were admitted to neurological wards with no stroke units $(7 \%)$, or to general wards (10\%) or to other departments. Considerable differences were found between provinces in terms of stroke unit treatment availability, with less than two thirds of patients hospitalised in the Łódzkie (65.1\%) province, but virtually all patients in the Świętokrzyskie, Pomorskie and Kujawsko-Pomorskie provinces. In most provinces, stroke unit care was provided by high-volume centres (over 200 admitted patients) except for Mazowieckie, Śląskie, Podkarpackie and Lubelskie provinces, in which several centres provided care for a lower number of ischaemic stroke patients (Tab. 1).

The crude and standardised rates of acute ischaemic stroke admission varied considerably between the different provinces, from 169.34 to 236.95 and from 109.32 to 169.49 per 100,000 inhabitants, respectively (Tab. 2 ). The mean values for the entire country were 189.95 and 130.43 per 100,000 inhabitants, respectively.
Substantial differences were observed for the thrombolysis implementation rate. While there were provinces that reported its use for $7 \%$ of ischaemic stroke patients only, there were also provinces that reported it twice as often (Tab. 3). A similar discrepancy was observed for admission to centres reporting thrombolysis. In the Kujawko-Pomorskie, Świętokrzyskie and Pomorskie provinces, virtually all (99\%) stroke patients were hospitalised in centres offering thrombolysis, while that figure was only $65 \%$ in the Łódzkie province. In general, $14 \%$ of Polish stroke patients were still hospitalised in a centre which reported no thrombolysis treatment. The corresponding percentage of patients hospitalised in centres with a high thrombolysis rate (over $10 \%$ ) was $67.54 \%$ and varied from 39.45 to $90.82 \%$.

Providing rehabilitation within 30 days of stroke onset was declared for $31.61 \%$ of patients, and ranged from $25.03 \%$ (Lubelskie province) to $37.73 \%$ (Śląskie province).

The variability of the median length of stay was more intra-province than inter-province (i.e. there were differences between centres in the same province with the lowest and highest median values).

Comparing patients' permanent residences to the locations where stroke healthcare was provided revealed a transfer rate of only $5 \%$. 
Table 2. Ischaemic stroke hospital admission data (rate per 100,000 inhabitants — 2017)

\begin{tabular}{|c|c|c|c|c|c|}
\hline Province & $\begin{array}{l}\text { Crude ischaemic } \\
\text { stroke patients } \\
\text { rates }\end{array}$ & $\begin{array}{c}\text { Standardised ischaemic } \\
\text { stroke patients rates } \\
(95 \% \mathrm{CI})\end{array}$ & Lower limit & Upper limit & $\begin{array}{l}\text { Hospital admission } \\
\text { rates for general po- } \\
\text { pulation }\end{array}$ \\
\hline Dolnośląskie & 185.92 & 122.0264 & 118.7705 & 125.2824 & 195.84 \\
\hline Kujawsko-Pomorskie & 186.61 & 130.9012 & 126.7860 & 135.0164 & 192.42 \\
\hline Lubelskie & 197.72 & 125.5782 & 121.7848 & 129.3716 & 205.00 \\
\hline Lubuskie & 236.95 & 169.4932 & 162.7247 & 176.2616 & 251.32 \\
\hline Łódzkie & 210.20 & 130.4038 & 126.8638 & 133.9438 & 217.38 \\
\hline Matopolskie & 169.34 & 116.5921 & 113.5742 & 119.6099 & 180.29 \\
\hline Mazowieckie & 171.74 & 113.3548 & 111.0419 & 115.6678 & 178.48 \\
\hline Opolskie & 203.80 & 130.1942 & 124.5165 & 135.8719 & 212.78 \\
\hline Podkarpackie & 190.02 & 131.6283 & 127.5708 & 135.6858 & 197.77 \\
\hline Podlaskie & 174.74 & 109.3261 & 104.6175 & 114.0347 & 181.83 \\
\hline Pomorskie & 189.03 & 137.1924 & 133.1317 & 141.2531 & 197.35 \\
\hline Śląskie & 211.13 & 136.1516 & 133.4297 & 138.8735 & 219.81 \\
\hline Świętokrzyskie & 223.97 & 138.5972 & 133.4626 & 143.7318 & 232.45 \\
\hline Warmińsko-Mazurskie & 189.85 & 139.3403 & 134.1075 & 144.5730 & 198.57 \\
\hline Wielkopolskie & 180.66 & 133.3310 & 130.0375 & 136.6244 & 190.10 \\
\hline Zachodniopomorskie & 181.24 & 122.7501 & 118.4241 & 127.0761 & 187.16 \\
\hline Poland & 189.95 & 130.4288 & 126.3027 & 134.5549 & 198.65 \\
\hline
\end{tabular}

Note: Columns 3, 4. 5: Age-standardised admission rates per 100,000 inhabitants for all ages up to $90+$ using the 2013 European Standard Population (ESP)

Table 3. Thrombolysis in Poland - 2017

\begin{tabular}{|c|c|c|c|c|c|}
\hline Province & $\begin{array}{c}\text { Thrombolysis } \\
\text { rate }(\%)\end{array}$ & $\begin{array}{l}\text { Number of cen- } \\
\text { ters reporting } \\
\text { thrombolysis in } \\
\text { acute ischaemic } \\
\text { stroke }\end{array}$ & $\begin{array}{l}\text { Percentage of pa- } \\
\text { tients hospitalised } \\
\text { in centres offering } \\
\text { thrombolysis }\end{array}$ & $\begin{array}{c}\text { Number of cen- } \\
\text { tres with throm- } \\
\text { bolysis rate over } \\
10 \%\end{array}$ & $\begin{array}{c}\text { Percentage of all acute ischa- } \\
\text { emic stroke patients hospi- } \\
\text { talised in } \\
\text { centres reporting over } 10 \% \\
\text { thrombolysis rate }\end{array}$ \\
\hline Dolnośląskie & 12.24 & 11 & 77.67 & 9 & 71.38 \\
\hline Kujawsko-Pomorskie & 15.59 & 10 & 97.38 & 8 & 81.49 \\
\hline Lubelskie & 11.84 & 14 & 89.64 & 9 & 58.10 \\
\hline Lubuskie & 9.43 & 5 & 88.67 & 1 & 39.45 \\
\hline Łódzkie & 11.91 & 10 & 65.07 & 8 & 52.05 \\
\hline Matopolskie & 12.33 & 15 & 85.96 & 13 & 78.51 \\
\hline Mazowieckie & 13.34 & 24 & 90.87 & 19 & 73.28 \\
\hline Opolskie & 14.22 & 3 & 93.66 & 2 & 78.36 \\
\hline Podkarpackie & 17.78 & 15 & 90.40 & 15 & 90.82 \\
\hline Podlaskie & 6.87 & 4 & 79.77 & 2 & 33.07 \\
\hline Pomorskie & 15.29 & 11 & 96.78 & 10 & 86.49 \\
\hline Śląskie & 11.83 & 26 & 86.95 & 17 & 61.08 \\
\hline Świętokrzyskie & 14.63 & 7 & 97.14 & 5 & 75.34 \\
\hline Warmińsko-Mazurskie & 11.58 & 7 & 75.55 & 7 & 74.92 \\
\hline Wielkopolskie & 12.75 & 12 & 73.14 & 8 & 51.61 \\
\hline Zachodniopomorskie & 13.81 & 7 & 90.75 & 5 & 64.73 \\
\hline Poland & 12.94 & 181 & 85.66 & 138 & 67.54 \\
\hline
\end{tabular}

Note: ICD-9 codes of thrombolysis: 99.10, 99.101, 99.102, 99.10399 .104 
Finally, the 30-day and 90-day adjusted mortality rates varied between provinces, from $14.42 \%$ (Pomorskie province) to $23.48 \%$ (Podlaskie province), and from $20.23 \%$ (Kujawsko-Pomorskie province) to $26.02 \%$ (Podlaskie province), respectively (Tab. 4).

\section{Discussion}

Over the last decade, the standard of stroke care in Poland has markedly improved, mainly due to the development of a network of stroke units. Most recent studies, both national and regional, have reported decreasing early and late fatality rates as well as lower admission rates, not only for first-ever but also recurrent strokes [14, 16, 17].

However, variations in selected indicators of acute ischaemic stroke care and outcomes across all Polish provinces are still common. Epidemiological, geographical and infrastructural differences across the country can explain some of these variations, but they are mostly caused by differences in local care organisation, with extensive room for improvement in multiple indicators that are linked to the functional outcome of stroke victims such as the rate of patients treated at stroke units, the rate of thrombolysis, or the availability of rehabilitation. Hospital practices and early prognosis require corrections and then further long-term monitoring and analysis, in the context of local interpretation and undertakings.

It is vital to propose optimal acute stroke care to facilitate early access not only to thrombolysis but also thrombectomy effective for selected stroke patients. Invasive (endovascular) treatment of ischaemic stroke was beyond the scope of this analysis, because at that time it was not funded from public sources, and performed only in a few hospitals in the country. Further studies should take this issue into account.

The high ischaemic stroke in-hospital admission rate, of over 198.65 per 100,000 population, could be slightly inflated by misreporting and overclaiming for that diagnosis. But even taking that into account, it clearly indicated increased stroke incidence compared to previous epidemiological studies [18].

It is worth noting that this analysis included only hospital admission due to acute stroke, which means that all pre-hospital case fatalities and potential outpatient acute ischaemic stroke management were ignored. However, given the organisation of the Polish healthcare system, it is unlikely that the latter would change the results significantly. Nevertheless, this analysis should not be perceived as an epidemiological study with case ascertainment and an overlapping source of data.

The great majority (almost 86\%) of stroke patients in Poland are treated in stroke units. Unfortunately, $17 \%$ of stroke unit patients are hospitalised for up to seven days (data not presented) and could not be reported with DRG codes specific to the individual stroke unit. As a consequence, treatment for a considerable number of patients in stroke units is financed in the same manner as in non-stroke units. This can result in unnecessarily prolonged hospital stays for minor stroke patients in Polish stroke units.

The thrombolysis rate is often regarded as one of the most important indicators of acute stroke care quality [19]. In Poland, this overall rate is lower than in many European Union countries, although it is much higher than in most countries in the world [20]. A survey conducted in 44 European countries in 2016/2017 showed a low thrombolysis rate in Poland [21]. Since then, it has increased substantially, yet unevenly as reported in our study.

Early ischaemic stroke mortality remains quite high in Poland compared to other European countries, and this will require special consideration and resources to overcome [22]. Unfortunately, no Polish official databases include modified Rankin scale results, which might provide more robust information on the general care of stroke patients than the mortality figure alone. Nevertheless, the differences in ischaemic stroke hospital admissions, as well as early and late stroke outcomes, are unlikely to result only from differences in comorbidities and demographics.

\section{Limitations}

A retrospective design and the analysis of data collected for financial rather than clinical or research purposes are the main limitations of this study. Therefore, the analyses were restricted to only those most likely to be unaffected by reporting bias. Poland as a country forms a single public payer for healthcare, which makes claims data highly comprehensive. Consequently, cross-regional analysis could be affected by patients being transferred between neighbouring provinces. The places is residence of patients and the locations in which healthcare was provided were analysed, and it was discovered that a transfer rate is only $5 \%$.

In-hospital mortality rates were reported but not interpreted because they could have been affected by acute stroke care organisation, e.g. early discharge in centres with facilitated access or on-site rehabilitation units. Therefore, the research concentrated on 10-, 30- and 90-day mortality rates, for which data is complete.

Funding: This study was based on the project 'Maps of Health Needs - Database of Systemic and Implementation Analyses' co-financed by the European Union from the European Social Fund as part of the Operational Programme Knowledge Education Development. The National Health Fund data reported in Poland was evaluated. The authors of this study report no conflict of interest. The approval of bioethical committees was not required. 


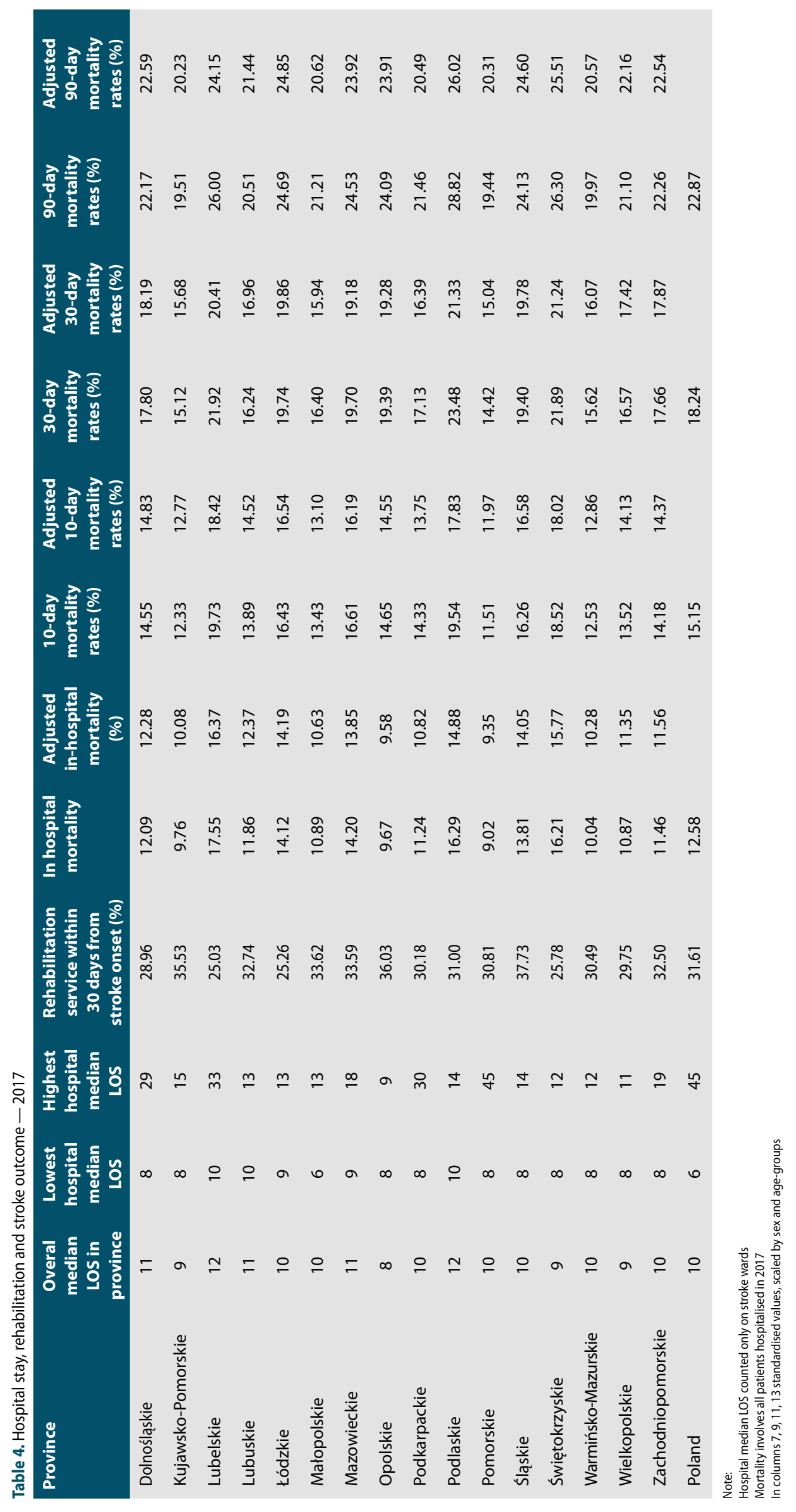




\section{References}

1. Collaborators, 2016 SG. Global, regional, and national burden of stroke, 1990-2016: a systematic analysis for the Global Burden of Disease Study 2016. Lancet Neurol. 2019: p. : 439-458.

2. Sarzyńska-Długosz I, Skowrońska M, Członkowska A. Organization of acute stroke services in Poland - Polish Stroke Unit Network development. Neurol Neurochir Pol. 2013; 47(1): 3-7, doi: 10.5114/ ninp.2013.32934, indexed in Pubmed: 23487288.

3. Jauch EC, Saver JL, Adams HP, et al. American Heart Association Stroke Council, Council on Cardiovascular Nursing, Council on Peripheral Vascular Disease, Council on Clinical Cardiology. Guidelines for the early management of patients with acute ischemic stroke: a guideline for healthcare professionals from the American Heart Association/ American Stroke Association. Stroke. 2013; 44(3): 870-947, doi: 10.1161/STR.0b013e318284056a, indexed in Pubmed: 23370205.

4. Ryglewicz D, Polakowska M, Lechowicz W, et al. Stroke mortality rates in Poland did not decline between 1984 and 1992. Stroke. 1997; 28(4): 752-757, doi: 10.1161/01.str.28.4.752, indexed in Pubmed: 9099191.

5. Niewada M, Sarzyńska-Długosz IM, Skowrońska M, et al. Pharmacotherapy prior to and in acute ischaemic stroke. The use of pharmacotherapy and drug-associated outcomes in real world practice - findings from the Polish Hospital Stroke Registry. Neurol Neurochir Pol. 2013; 47(6): 509-516, doi: 10.5114/ninp.2013.39067, indexed in Pubmed: 24374995.

6. Niewada M, Skowrońska M, Sarzyńska-Długosz IM, et al. Pharmacotherapy prior to and in acute haemorrhagic stroke. The use of pharmacotherapy and drugs associated outcomes in real-world practice - findings from the Polish Hospital Stroke Registry. Neurol Neurochir Pol. 2013; 47(6): 517-524, doi: 10.5114/ninp.2013.39068, indexed in Pubmed: 24374996.

7. Niewada M, Skowrońska M, Ryglewicz D, et al. Polish National Stroke Prevention and Treatment Collaborative Group. Acute ischemic stroke care and outcome in centers participating in the Polish National Stroke Prevention and Treatment Registry. Stroke. 2006; 37(7): 1837-1843, doi: 10.1161/01.STR.0000226992.39847.ef, indexed in Pubmed: 16741176.

8. Niewada M, Jezierska-Ostapczuk A, Skowrońska M, et al. Weekend versus weekday admissions in Polish stroke centres - could admission day affect prognosis in Polish ischaemic stroke patients? Neurol Neurochir Pol. 2012; 46(1): 15-21, doi: 10.5114/ninp.2012.27209, indexed in Pubmed: 22426758.

9. Sienkiewicz-Jarosz H, Głuszkiewicz M, Pniewski J, et al. Incidence and case fatality rates of first-ever stroke - comparison of data from two prospective population-based studies conducted in Warsaw. Neurol Neurochir Pol. 2011; 45(3): 207-212, doi: 10.1016/s00283843(14)60073-6, indexed in Pubmed: 21866477.

10. Szczuchniak W, Kozera G, Sobolewski P, et al. Pomeranian Stroke Registry collaborators. Length of stay in emergency department and cerebral intravenous thrombolysis in community hospitals. Eur J Emerg Med. 2017; 24(3): 208-216, doi: 10.1097/ MEJ.0000000000000330, indexed in Pubmed: 26479737.
11. Klimkowicz A, Dziedzic T, Slowik A, et al. Incidence of pre- and poststroke dementia: cracow stroke registry. Dement Geriatr Cogn Disord. 2002; 14(3): 137-140, doi: 10.1159/000063599, indexed in Pubmed: 12218256.

12. Starostka-Tatar A, Łabuz-Roszak B, Skrzypek M, et al. Characteristics of hospitalizations due to acute stroke in the Silesian Province, Poland, between 2009 and 2015. Neurol Neurochir Pol. 2018; 52(2): 252-262, doi: 10.1016/j.pjnns.2017.11.010, indexed in Pubmed: 29221869.

13. Kozera G, Chwojnicki K, Gójska-Grymajło A, et al. Pomeranian Stroke Register collaborators. Pre-hospital delays and intravenous thrombolysis in urban and rural areas. Acta Neurol Scand. 2012; 126(3): 171-177, doi: 10.1111/j.1600-0404.2011.01616.x, indexed in Pubmed: 22077692.

14. Chwojnicki K, Ryglewicz D, Wojtyniak B, et al. Acute Ischemic Stroke Hospital Admissions, Treatment, and Outcomes in Poland in 20092013. Front Neurol. 2018; 9: 134, doi: 10.3389/fneur.2018.00134, indexed in Pubmed: 29593634.

15. Pace M, Cayotte E, Agafitei L, et al. Revision of the European Standard Population. Report of Eurostat's task force. Luxembourg: European Commission, Eurostat, Publications Office. ; 2013.

16. Gierlotka M, Labuz-Roszak B, Wojtyniak B, et al. Early and One-Year Outcomes of Acute Stroke in the Industrial Region of Poland During the Decade 2006-2015: The Silesian Stroke Registry. Neuroepidemiology. 2018; 50(3-4): 183-194, doi: 10.1159/000487324, indexed in Pubmed: 29587253.

17. Łabuz-Roszak B, Skrzypek M, Starostka-Tatar A, et al. Epidemiological analysis of hospitalisations due to recurrent stroke in the Silesian Province, Poland, between 2009 and 2015. Neurol Neurochir Pol. 2019; 53(4): 277-290, doi: 10.5603/PJNNS.a2019.0034, indexed in Pubmed: 31441494.

18. Ryglewicz D, Baranska-Gieruszczak M, Czlonkowska A, et al. A prospective community-based study of stroke in Warsaw, Poland. Stroke. 1994; 25(3): 547-551, doi: 10.1161/01.str.25.3.547, indexed in Pubmed: 8128505.

19. Schwamm LH, Fonarow GC, Reeves MJ, et al. Get With the Guidelines-Stroke is associated with sustained improvement in care for patients hospitalized with acute stroke or transient ischemic attack. Circulation. 2009; 119(1): 107-115, doi: 10.1161/CIRCULATIONAHA.108.783688, indexed in Pubmed: 19075103.

20. Stevens E, McKevitt C, Emmett E, et al. The Burden of Stroke in Europe, the Challenge for Policy Makers. London: King's College London for the Stroke Alliance for Europe (SAFE), Stroke Alliance for Europe; 2017.

21. Aguiar de Sousa D, von Martial R, Abilleira S, et al. Access to and delivery of acute ischaemic stroke treatments: A survey of national scientific societies and stroke experts in 44 European countries. Eur Stroke J. 2019; 4(1): 13-28, doi: 10.1177/2396987318786023, indexed in Pubmed: 31165091.

22. Budincevic H, Tiu C, Bereczki D, et al. CEESS Working Group. Management of ischemic stroke in Central and Eastern Europe. Int J Stroke. 2015; 10 Suppl A100: 125-127, doi: 10.1111/ijs.12575, indexed in Pubmed: 26179030. 